\title{
FPGA Implementation of Simplified SVPWM Algorithm for Three Phase Voltage Source Inverter
}

\author{
D. N. Sonawane, M. S. Sutaone , B. N. Choudhari and Abhijeet Badurkar
}

\begin{abstract}
A resource efficient with low computational overheads SVPWM algorithm for three phase voltage source inverter which is used to supply variable voltage and variable frequency to three phase $\mathrm{AC}$ drives is proposed in this paper. Because of its advantages like lower switching losses, higher dcbus utilization SVPWM scheme becomes the preferred PWM technique for various three-phase power converter applications. Conventional SVPWM algorithm involves complex mathematics and requires more hardware resources to implement and takes more time for its execution. The Field Programmable Gate Arrays (FPGAs) offer high computational ability and flexibility due to their parallel execution and reconfigurable hardware. Hence the scheme suggests the implementation of a resource efficient algorithm with low computational overheads for SVPWM generation using FPGA and obtains higher sampling rates with minimal use of hardware resources. Resource utilization of proposed algorithm obtained is $4 \%$ for XILINX XC3S500E processor operating at $50 \mathrm{MHz}$. The output fundamental frequency can be adjusted from $0.1 \mathrm{~Hz}$ to $1500 \mathrm{~Hz}$ and $\mathrm{PWM}$ switching frequency can be set from 200 to $50 \mathrm{KHz}$. The adjustable delay time logic for PWM gating signals is also implemented. The proposed algorithm is tested for 3-phase induction motor with VSI and the experimented results are validated.
\end{abstract}

Index Terms-Digital Control, FPGA, SVPWM, Xilinx XC3S500E

\section{INTRODUCTION}

Variable voltage and frequency supply for ac drive is invariably obtained from three-phase Voltage Source Inverter. A number of PWM techniques have been presented to obtain variable voltage and variable frequency supply[4]. Space Vector Pulsewidth Modulation has become one of the most important PWM method for three-phase voltage source inverters[5]. It has an advantages over carrier-based sine tringle pwm such as higher dc bus utilization, lower switching losses and less harmonic distortions [14].

In order to implement SVPWM algorithm DSPs are widely used but the execution of SVPWM algorithm in less number of machine cycles is need of many applications which can not be satisfied with conventioanl DSPs because

Manuscript received June 30, 2010

D. N. Sonawane is with the Department of Instrumentation and Control of College of Engineering, Pune-411005, MH,INDIA (91-020- 25507185; fax: 91-020-25507299; e-mail: dns.instru@ coep.ac.in).

M. S. Sutaone is with Department of Electronics and Communication of College of Engineering, Pune-411005, MH, INDIA (91-020- 25507141; fax: 91-020-25507299; e-mail: mssutaone@ extc.coep.org.in)

B. N. Choudhari is with Department of Electrical Engineering of College of Engineering, Pune-411005, MH, INDIA (91-020- 25507112; fax: 91-020-25507299; e-mail: bnc.elec@ coep.ac.in) they executes instructions sequentially and thus requires more time to compute. Whereas, field programmable gate array (FPGA) performs the entire procedures with concurrent operation by using its reconfigurable hardware and parallel processing. Employing FPGA to realize PWM strategies provides advantages such as rapid prototyping, simple hardware and software design, higher switching frequency and reduction of computational overheads [5]. Computational Complexity and resource utiliazation of conventional SVPWM algorithm increases thus the execution time with number of levels of converter [2].

In this paper, a resource efficient SVPWM algorithm is proposed which reduces computational overheads and solves the problem of high sampling time in real time applications. The proposed algorithm uses only adders, subtractors, comparators, shifters, etc to be implemeted using FPGA's and takes less number of resources and execution time than conventional algorithm. Finally, experimental results from an inverter prototype are presented to confirm the validity and performance of the designed SVPWM algorithm. Fig.1 shows the open loop control scheme for three phase induction motor which is used for testing and validation of algorithm.

This paper is organized as follows. Section II introduces conventional SVPWM algorithm and mathematics involved in it. Section III discusses simplified SVPWM algorithm. Section IV describes FPGA implementation of proposed simplified SVPWM algorithm and experimental results. Finally conclusion is in Section V.

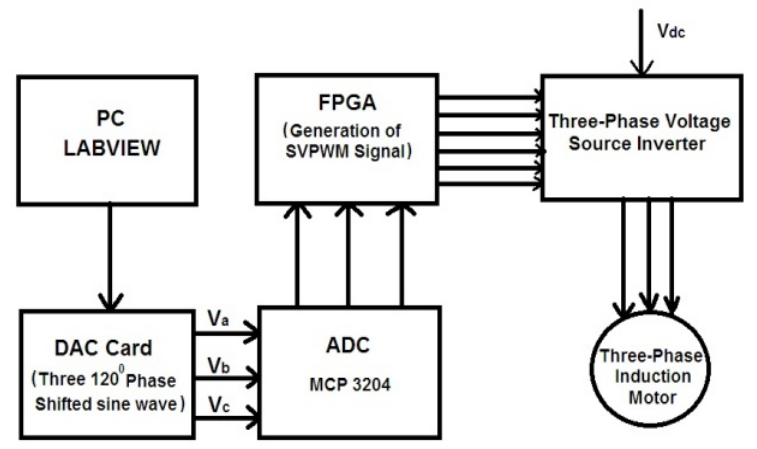

Fig. 1 Open loop scheme for three-phase induction motor

\section{Conventional Svpwm Algorithm}

To implement the space vector PWM, the voltage equations in the abc reference frame can be transformed into 
the stationary $d-q$ reference frame that consists of the horizontal (d) and vertical (q) axis as depicted in Fig. 2

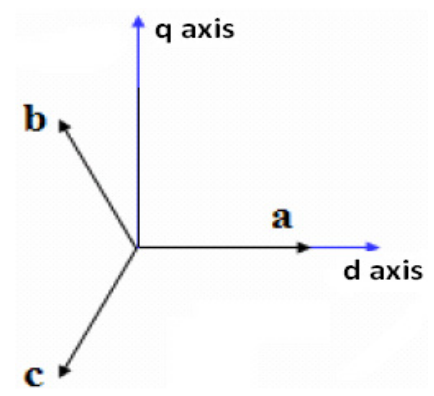

Fig. 2 Relationship between a-b-c reference frame and stationay d-q frame

The relationship is expressed as

$$
\begin{gathered}
f_{d q 0}=K s f_{a b c} \\
\text { Where } K s=\left[\begin{array}{ccc}
1 & 1 / 2 & -1 / 2 \\
0 & \sqrt{3} / 2 & -\sqrt{3} / 2 \\
1 / 2 & 1 / 2 & 1 / 2
\end{array}\right]
\end{gathered}
$$

The transformation is equivalent to an orthogonal projection of $a-b-c$ reference frame onto two dimensional perpendiculars to the equivalent $\mathrm{d}-\mathrm{q}$ plane in a three dimensional co-ordinate system. As a result six nonzero and two zero vectors are obtained. The six non zero vectors are shape to hexagonal as shown in fig. 3(a). The angle between any two non zero adjacent vectors is $60^{\circ}$. The objective of SVPWM is to approximate reference voltage vector $V_{\text {ref }}$ using eight switching pattern. Therefore, space vector PWM can be implemented by following three steps:

- Determining $\mathrm{V}_{\mathrm{d}}, \mathrm{V}_{\mathrm{q}}, \mathrm{V}_{\text {ref }}$ and angle $\alpha$ for sector

- Determining the time duration T1, T2 and T0

- Determining the switching time of each switching devices $(\mathrm{S} 1 \sim \mathrm{S} 6)$

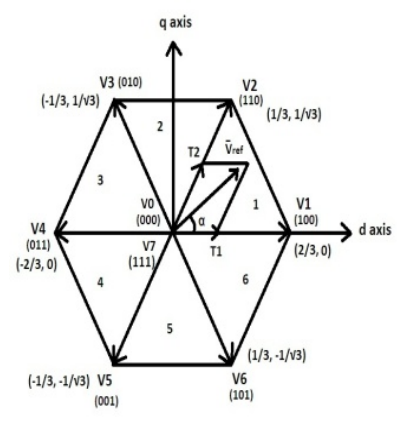

(a)

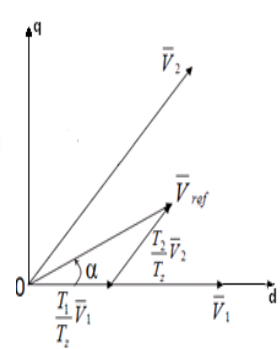

(b)
Fig. 3 (a) d-q transfomation of Space Voltage Vectors in different sectors

Fig 3 (b) Space Vector time calculations with Vref

The relationship between switching variable vector and phase voltage vector $\left[\mathrm{V}_{\mathrm{a}} \mathrm{V}_{\mathrm{b}} \mathrm{V}_{\mathrm{c}}\right]$ can be expressed as follows.

$$
\begin{aligned}
V_{d}= & V_{a n}-V_{b n} \cdot \cos 60-V_{c n} \cdot \cos 60 \\
= & V_{a n}-1 / 2 V_{b n}-1 / 2 V_{c n} \\
V_{q}= & 0+V_{b n} \cdot \cos 30-V_{c n} \cdot \cos 30 \\
& =\sqrt{3} / 2 V_{b n}-\sqrt{3} / 2 V_{c n}
\end{aligned}
$$

$$
\therefore\left[\begin{array}{c}
\mathrm{V}_{\mathrm{d}} \\
\mathrm{V}_{\mathrm{q}}
\end{array}\right]=\frac{2}{3}\left[\begin{array}{ccc}
1 & \frac{-1}{2} & \frac{-1}{2} \\
0 & \frac{\sqrt{3}}{2} & \frac{-\sqrt{3}}{2}
\end{array}\right]\left[\begin{array}{c}
\mathrm{V}_{\mathrm{an}} \\
\mathrm{V}_{\mathrm{bn}} \\
\mathrm{V}_{\mathrm{cn}}
\end{array}\right]
$$

From fig. 3 (b), the reference vectror $V_{\text {ref }}$ is calculated as

$$
\begin{aligned}
\left|V_{r e f}\right| & =\sqrt{V_{d}^{2}+V_{q}^{2}} \\
\alpha & =\tan ^{-1}\left(V_{q} / V_{d}\right)
\end{aligned}
$$

In general, $V_{\text {ref }}$ in ' $n$ ' sector is obtained by two adjecent non-zero vectors $\left(\mathrm{V}_{\mathrm{j}}, \mathrm{V}_{\mathrm{j}+1}\right)$ and two-zero vectors. $\mathrm{V}_{\text {ref }}$ is expressed as

$$
V_{\text {ref }}=\frac{T_{n}}{T_{z}} \cdot V n+\frac{T_{n+1}}{T_{z}} \cdot V_{n+1}
$$

where $T_{n} \& T_{n+1}$ are on time of $V_{n}$ and $V_{n+1}$ during each sampling period (Tz) respectively and ' $n$ ' is the sector number in which $\mathrm{V}_{\text {ref }}$ resides. Fig 3 (b) shows the space vectro time representation with $\mathrm{V}_{\text {ref }}$ for sector 1 . The magnitude of non zero sapce vector always $\|\mathrm{Vj}\|=2 \mathrm{~V}_{\mathrm{dc}} / 3$. The sectors are identifide depending on values of angle ' $\alpha$ '.

The switching time duration $\mathrm{T} 1, \mathrm{~T} 2$ and $\mathrm{T} 0$ for a perticular sector can be calculated from following equations .

$$
\begin{aligned}
& T_{1}=\frac{\sqrt{3} \cdot T_{z}}{V d c}\left[\sin \left(\frac{p i}{3} n\right) V_{d}-\cos \left(\frac{p i}{3} n\right) V_{q}\right] \\
& T_{2}=\frac{\sqrt{3} \cdot T_{z}}{V d c}\left\{-\sin \left[\frac{p i}{3}(n-1)\right] V_{d}+\cos \left[\frac{p i}{3}(n-1)\right] V_{q}\right\} \\
& T_{0}=T_{Z}-T_{n}-T_{n+1}
\end{aligned}
$$

The switching time of each switching devices (S1 S6) per sector is given as per table I

TABLE I SWITCHING TIME AT EACH SECTOR

\begin{tabular}{|l|l|l|}
\hline SECTOR & S1, $\mathbf{S 3}, \mathbf{S 5}$ & S2, $\mathbf{S}$, $\mathbf{S 6}$ \\
\hline 1 & $\mathrm{~S} 1=\mathrm{T} 1+\mathrm{T} 2+\mathrm{T} 0 / 2$ & $\mathrm{~S} 4=\mathrm{T} 0 / 2$ \\
& $\mathrm{~S} 3=\mathrm{T} 2+\mathrm{T} 0 / 2$ & $\mathrm{~S} 6=\mathrm{T} 1+\mathrm{T} 0 / 2$ \\
& $\mathrm{~S} 5=\mathrm{T} 0 / 2$ & $\mathrm{~S} 2=\mathrm{T} 1+\mathrm{T} 2+\mathrm{T} 0 / 2$ \\
\hline 2 & $\mathrm{~S} 1=\mathrm{T} 1+\mathrm{T} 0 / 2$ & $\mathrm{~S} 4=\mathrm{T} 2+\mathrm{T} 0 / 2$ \\
& $\mathrm{~S} 3=\mathrm{T} 1+\mathrm{T} 2+\mathrm{T} 0 / 2$ & $\mathrm{~S} 6=\mathrm{T} 0 / 2$ \\
& $\mathrm{~S} 5=\mathrm{T} 0 / 2$ & $\mathrm{~S} 2=\mathrm{T} 1+\mathrm{T} 2+\mathrm{T} 0 / 2$ \\
\hline 3 & $\mathrm{~S} 1=\mathrm{T} 0 / 2$ & $\mathrm{~S} 4=\mathrm{T} 1+\mathrm{T} 2+\mathrm{T} 0 / 2$ \\
& $\mathrm{~S} 3=\mathrm{T} 1+\mathrm{T} 2+\mathrm{T} 0 / 2$ & $\mathrm{~S} 6=\mathrm{T} 0 / 2$ \\
& $\mathrm{~S} 5=\mathrm{T} 1+\mathrm{T} 2$ & $\mathrm{~S} 2=\mathrm{T} 1+\mathrm{T} 0 / 2$ \\
\hline 4 & $\mathrm{~S} 1=\mathrm{T} 0 / 2$ & $\mathrm{~S} 4=\mathrm{T} 1+\mathrm{T} 2+\mathrm{T} 0 / 2$ \\
& $\mathrm{~S} 3=\mathrm{T} 1+\mathrm{T} 0 / 2$ & $\mathrm{~S} 6=\mathrm{T} 2+\mathrm{T} 0 / 2$ \\
& $\mathrm{~S} 5=\mathrm{T} 1+\mathrm{T} 2+\mathrm{T} 0 / 2$ & $\mathrm{~S} 2=\mathrm{T} 0 / 2$ \\
\hline 5 & $\mathrm{~S} 1=\mathrm{T} 2+\mathrm{T} 0 / 2$ & $\mathrm{~S} 4=\mathrm{T} 1+\mathrm{T} 0 / 2$ \\
& $\mathrm{~S} 3=\mathrm{T} 0 / 2$ & $\mathrm{~S} 6=\mathrm{T} 1+\mathrm{T} 2+\mathrm{T} 0 / 2$ \\
& $\mathrm{~S} 5=\mathrm{T} 1+\mathrm{T} 2+\mathrm{T} 0 / 2$ & $\mathrm{~S} 2=\mathrm{T} 0 / 2$ \\
\hline 6 & $\mathrm{~S} 1=\mathrm{T} 1+\mathrm{T} 2+\mathrm{T} 0 / 2$ & $\mathrm{~S} 4=\mathrm{T} 0 / 2$ \\
& $\mathrm{~S} 3=\mathrm{T} 0 / 2$ & $\mathrm{~S} 6=\mathrm{T} 1+\mathrm{T} 2+\mathrm{T} 0 / 2$ \\
& $\mathrm{~S} 5=\mathrm{T} 1+\mathrm{T} 0 / 2$ & $\mathrm{~S} 2=\mathrm{T} 2+\mathrm{T} 0 / 2$ \\
\hline
\end{tabular}

From the above equations and fig 3 (a) and (b), the sector identification criterion of conventional algorithm involves 
floating point operations as to get angle that requires calculating inverse tan function. Because of sine function and square root values involved in computation switching time duration i.e. T1, T2 and T0, implementation of conventional algorithm using digital processor becomes difficult. In context with FPGA implementation the floating point operations and trigonometric functions increases resource utilization thus execution time. Attempt to be made to simplify mathematical equations which require only addition, subtraction, shifting, etc. to implement the SVPWM algorithm for three phase VSI.

\section{SIMPLIFIED ALGORITHM}

The conventional SVPWM algorithm includes $d-q$ transformation of three input voltages $\mathrm{V}_{\mathrm{an}}, \mathrm{V}_{\mathrm{bn}}$ and $\mathrm{V}_{\mathrm{cn}}$ as given by equation (4) this transformation requires value of $\sqrt{3}$ to be calculated it is difficult to implement floating point numbers using FPGA. Hence instead of $d-q$ transformation, intermediate transformation vectors are used. The eq. (3) can be written as:

$$
\begin{gathered}
V_{d}=\frac{2}{3} V a-\frac{1}{3} V b-\frac{1}{3} V c \& \\
V q=\frac{1}{\sqrt{3}} V b-\frac{1}{\sqrt{3}} V c \\
\therefore V d=\frac{1}{3}[2 V a-V b-V c] \\
V q=\frac{1}{\sqrt{3}}[V b-V c]
\end{gathered}
$$

By defining intermediate variables as $\mathrm{X}_{\mathrm{d}}$ and $\mathrm{X}_{\mathrm{q}}$, the eq. (7) written as:

$$
\begin{aligned}
& X d=2 V a-V b-V c \quad \& \\
& X q=V b-V c
\end{aligned}
$$

By combining eq. (8) and (9), the $\mathrm{V}_{\mathrm{d}}$ and $\mathrm{V}_{\mathrm{q}}$ are expressed in terms of intermediate vectors as:

$$
\begin{aligned}
\therefore V d & =\frac{1}{3}[X d] \\
V q & =\frac{1}{\sqrt{3}}[X q]
\end{aligned}
$$

Hence the algorithm needs only to calculate $X_{d}$ and $X_{q}$ which requires simple operators namely shifter (for multiplication by 2), adder and subtractor. The corresponding $\mathrm{V}_{\mathrm{d}}$ and $\mathrm{V}_{\mathrm{q}}$ calculated by normalizing the values with $1 / 3$ and $1 / \sqrt{3}$ units.

The determination of sector depends only on the sign of $\mathrm{X}_{\mathrm{d}}$ and $\mathrm{X}_{\mathrm{q}}$ as per following rules. Determination of the sectors can be done by simply checking 3 conditions:

Condition 1: sign of $\mathrm{Xd}$

Condition 2: sign of $\mathrm{Xq}$

Condition 3: $|\mathrm{Xd}|>|\mathrm{Xq} / 2|$

The rules to find sectors:

Rule 1: if $(X d>0 \& X q>0 \&|X d|>|X q / 2|)$

\section{Sector- 1}

Rule 2: if $(\mathrm{Xd}>0 \& \mathrm{Xq}>0 \&|\mathrm{Xd}|<|\mathrm{Xq} / 2|)$

Sector- 2

OR

if $(\mathrm{Xd}<0 \& \mathrm{Xq}>0 \&|\mathrm{Xd}|<|\mathrm{Xq} / 2|)$

Sector- 2

Rule 3: if $(\mathrm{Xd}<0 \& \mathrm{Xq}>0 \&|\mathrm{Xd}|>|\mathrm{Xq} / 2|)$

Sector-3

Rule 4: if $(\mathrm{Xd}<0 \& \mathrm{Xq}<0 \&|\mathrm{Xd}|>|\mathrm{Xq} / 2|)$

\section{Sector-4}

Rule 5: if $(\mathrm{Xd}>0 \& \mathrm{Xq}<0 \&|\mathrm{Xd}|<|\mathrm{Xq} / 2|)$

Sector-5

OR

$$
\text { if }(\mathrm{Xd}<0 \& \mathrm{Xq}<0 \&|\mathrm{Xd}|<|\mathrm{Xq} / 2|)
$$

\section{Sector-5}

Rule 6: if $(\mathrm{Xd}>0 \& \mathrm{Xq}<0 \&|\mathrm{Xd}|>|\mathrm{Xq} / 2|)$

Sector-6

For a symmetric space vector PWM, the output voltage i.e. $\mathrm{X}_{\mathrm{d}}$ and $\mathrm{X}_{\mathrm{q}}$ can be in any of the sector 1 to sector 6 is given by the equation

$$
\left[\begin{array}{c}
\mathrm{T}_{\mathrm{n}} \\
\mathrm{T}_{\mathrm{n}+1}
\end{array}\right]=\mathrm{T}_{\mathrm{PWM}} \mathrm{M}_{0}\left[\begin{array}{l}
\mathrm{X}_{\mathrm{d}} \\
\mathrm{X}_{\mathrm{q}}
\end{array}\right]
$$

Eq. (11) shows that every PWM period, the output voltages are approximated as $\left(\mathrm{T}_{\mathrm{z}} / \mathrm{V}_{\mathrm{dc}}\right.$ by switching between the two non zero basic vectors that border the sector of the current output voltages. The sum of $T_{n}$ and $T_{n+1}$ should be less than or equal to $\mathrm{T}_{\mathrm{PWM}}$ and rest of period the switching time should be $\mathrm{T}_{0}$. The $\mathrm{M}_{0}$ is called as decomposition matrix, given as

$$
M_{0}=\left[\begin{array}{ll}
M_{00} & M_{01} \\
M_{10} & M_{11}
\end{array}\right]
$$

Applying equation (10) to (6), the switching time can be calculated as

$$
=\left[\begin{array}{cc}
\frac{2}{\sqrt{3}} \sin \left(\frac{p i}{3} n\right) & -\cos \left(\frac{p i}{3} n\right) \\
-\frac{2}{\sqrt{3}} \sin \left[\frac{p i}{3}(n-1)\right] & \cos \left[\frac{p i}{3}(n-1)\right]
\end{array}\right]
$$

If $\mathrm{Vdc}$ is normalized with $\sqrt{3}$ per unit, and $\mathrm{Tz}$ is set to $\sqrt{3}$ per unit, the four coefficients in eq. (12) will alter their values according to the sector ' $n$ '. If reference vector is located in sector $I$, then ' $n$ ' $=1$, then $M_{00}=1, M_{01}=-1 / 2$, $\mathrm{M}_{10}=0$ and $\mathrm{M}_{11}=1$.

The coefficients of decomposition matrix according to sector is given in Table II

TABLE II COEFFICIENTS OF DECOMPOSITION MATRIX

\begin{tabular}{|c|c|c|c|c|c|c|}
\hline $\begin{array}{c}\text { Sector } \\
\text { 'n' }\end{array}$ & $\mathbf{1}$ & $\mathbf{2}$ & $\mathbf{3}$ & $\mathbf{4}$ & $\mathbf{5}$ & $\mathbf{6}$ \\
\hline $\mathrm{M}_{00}$ & 1 & 1 & 0 & -1 & -1 & 0 \\
\hline
\end{tabular}




\begin{tabular}{|c|c|c|c|c|c|c|}
\hline $\mathrm{M}_{01}$ & $-1 / 2$ & $1 / 2$ & 1 & $1 / 2$ & $-1 / 2$ & -1 \\
\hline $\mathrm{M}_{10}$ & 0 & -1 & -1 & 0 & 1 & 1 \\
\hline $\mathrm{M}_{11}$ & 1 & $1 / 2$ & $-1 / 2$ & -1 & $-1 / 2$ & $1 / 2$ \\
\hline
\end{tabular}

So from eq. (11) the switching times are calculated as

$$
\begin{aligned}
& {\left[\mathrm{T}_{\mathrm{n}}{ }^{\prime}\right]=\left[\begin{array}{ll}
\mathrm{M}_{00} & \mathrm{M}_{01}
\end{array}\right]\left[\begin{array}{l}
\mathrm{X}_{\mathrm{d}} \\
\mathrm{X}_{\mathrm{q}}
\end{array}\right]} \\
& {\left[\mathrm{T}_{\mathrm{n}+1}{ }^{\prime}\right]=\left[\begin{array}{ll}
\mathrm{M}_{10} & \mathrm{M}_{11}
\end{array}\right]\left[\begin{array}{l}
\mathrm{X}_{\mathrm{d}} \\
\mathrm{X}_{\mathrm{q}}
\end{array}\right]} \\
& {\left[\mathrm{T}_{0}{ }^{\prime}\right]=\sqrt{3}-\mathrm{T}_{\mathrm{n}}{ }^{\prime}+\mathrm{T}_{\mathrm{n}+1}{ }^{\prime}}
\end{aligned}
$$

The calculation for eq. (13) will requires simple operators such as shifters, adders and subtractors including $\mathrm{X}_{\mathrm{d}}$, and $\mathrm{X}_{\mathrm{q}}$. Thus the proposed algorithm reduces the complexity of conventional SVPWM algorithm.

\section{FPGA IMPLEMENTATION}

Fig. 4 shows the internal architecture of simplified SVPWM algorithm implemented using Spartan 3 FPGA (XILINX XC3S500E)

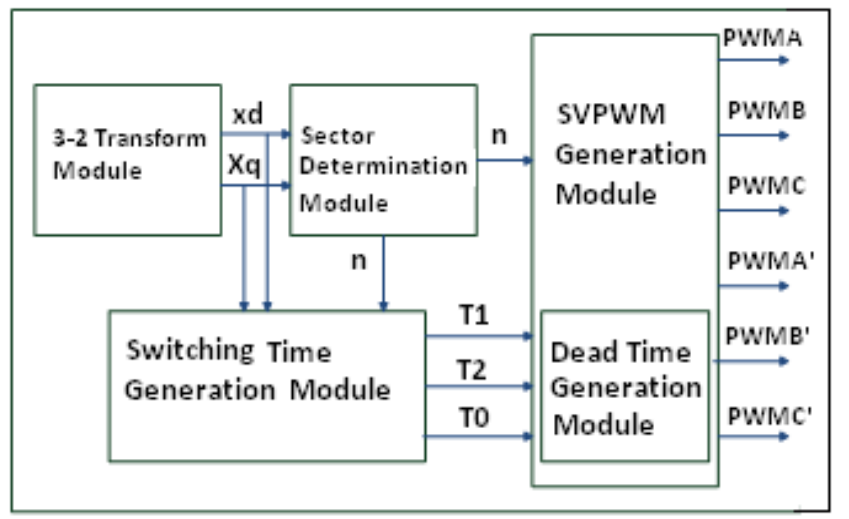

Fig. 4 Internal Architecture of Simplified SVPWM Algorithm

The architecture mainly consists of five major blocks

\section{3-2 Transformation Module:}

Values of three phase voltages i.e. $\mathrm{V}_{\mathrm{a}}, \mathrm{V}_{\mathrm{b}}, \mathrm{V}_{\mathrm{c}}$ is input to this block. This module transforms three phase voltage reference frame to two phase voltage reference frame using equations (10). To implement in FPGA the resources requires are only adders, and subtractors.

\section{Sector determination module:}

The input to this module is $\mathrm{X}_{\mathrm{d}}$ and $\mathrm{X}_{\mathrm{q}}$ values generated by three to two phase transformation module. This module checks three conditions as explained earlier and the corresponding sectors get determined as per the rules explained earlier.

Result of condition $\mathrm{X}_{\mathrm{d}}>0$ is stored in 1 bit variable as $\mathrm{C} 1$.

Result of condition $\mathrm{X}_{\mathrm{q}}>0$ is stored in 1 bit variable as $\mathrm{C} 2$

And result of condition $\left|\mathrm{X}_{\mathrm{d}}\right|>\left|\mathrm{X}_{\mathrm{q}} / 2\right|$ is stored as $\mathrm{C} 3$.

These variables are appended to form a three bit array named as sect. The array sect $=\{\mathrm{C} 1, \mathrm{C} 2, \mathrm{C} 3\}$. The sector can be determined from the value of sect according to following table:

\section{TABLE III VALUES OF ARRAYS ACCORDING TO SECTOR}

\begin{tabular}{|c|c|}
\hline Sector & Array value \\
\hline 1 & 7 \\
\hline 2 & 2,6 \\
\hline 3 & 3 \\
\hline 4 & 1 \\
\hline 5 & 0,4 \\
\hline 6 & 5 \\
\hline
\end{tabular}

For example, if $\mathrm{Xd}>0$, then $\mathrm{C} 1=1$ and $\mathrm{Xq}<0, \mathrm{C} 2=0$ and for $|\mathrm{Xd}|>|\mathrm{Xq} / 2|, \mathrm{C} 3=1$. So sect $=\{1,0,1\}=5$.

So according to table III, the sector 6 will get selected.

\section{Switching time calculation module:}

Switching time calculation requires values of $X_{d}, X_{q}$ and sectors. These values are calculated by two blocks as explained earlier. The values of parameters $\mathrm{T}_{\mathrm{n}}{ }^{\prime}$ and $\left.\mathrm{T}_{\mathrm{n}+1}{ }^{\prime}\right]$ are determined from equation (13). The coefficients of decomposition matrix and their values are obtained from table II based on sector number.

\section{Symmetrical PWM generation module:}

This module is the heart of this algorithm which is responsible for generation of six symmetrical PWM signals. This module requires sector number and switching time values calculated by previous blocks. The PWM switching frequency can be adjusted in this module. Dead time generation module is a part of this module.

Figure 5(a) and 5(b) shows the waveform produced for sector I and II as a sample.

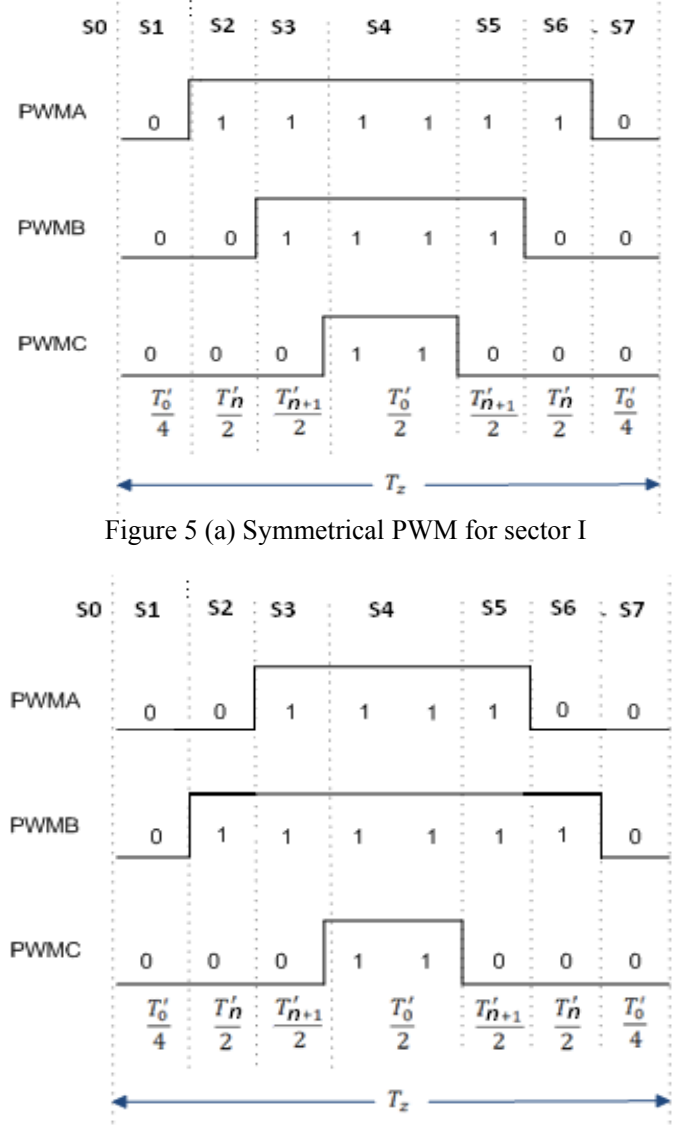

Figure 5 (b) Symmetrical PWM for sector II

Each waveform has following properties

1. Each PWM channel switches twice per PWM period except when duty cycle is 0 or $100 \%$ 
2. There is fixed switching order among the three PWM channels for each sector

According to figure 5 (a) and 5 (b) the values of different PWM outputs are changes only for the states S2, S3, S5, and S6 out of which the pattern of S2 and S6 are always same as well the pattern of S3 and S5 are always same, Hence 3 bit array (S2ar and S3ar) is created each for S2 (same for S6) and S3 (same for S5) respectively. Values are assigned to these arrays based on sector of $\mathrm{V}_{\text {ref }}$ according to table IV.

\section{TABLE IV SYMMETRICAL PWM OUTPUTS ACCORDING} TO STATES

\begin{tabular}{|l|c|c|c|c|c|c|c|}
\hline STATES & $\mathbf{N}$ & 1 & 2 & 3 & 4 & 5 & 6 \\
\hline \multirow{3}{*}{ S2,S6 } & PWMA & 1 & 0 & 0 & 0 & 0 & 1 \\
\cline { 2 - 8 } & PWMB & 0 & 1 & 1 & 0 & 0 & 0 \\
\cline { 2 - 8 } & PWMC & 0 & 0 & 0 & 1 & 1 & 0 \\
\hline \multirow{3}{*}{ S3,S5 } & PWMA & 1 & 1 & 0 & 0 & 1 & 1 \\
\cline { 2 - 8 } & PWMB & 1 & 1 & 1 & 1 & 0 & 0 \\
\cline { 2 - 8 } & PWMC & 0 & 0 & 1 & 1 & 1 & 1 \\
\hline
\end{tabular}

The value of switching time $T_{z}$ is kept equal to $V_{d c}$ for normalization.

A counter is set to 0 at the beginning of each switching period which counts up to $T_{z}$. The time step to this counter is adjustable. Larger time step means smaller frequency and vice versa. Thus the PWM frequency can be adjusted by adjusting the time step. For $\mathrm{C}<\mathrm{T}_{0} / 4$, PWMA, PWMB and PWMC are off. (Refer S1 state of fig.5). Then for $\mathrm{T}_{0} / 4 \leq \mathrm{C}$ $<\mathrm{T}_{\mathrm{n}}{ }^{\prime} / 2$, the PWMA, PWMB and PWMC are assigned values of S2ar which are sector dependent (state S2 of Fig.5). For state S3, the values of PWMA, PWMB and PWMC are assigned as given by $\mathrm{S} 3 \mathrm{ar}$.

This procedure is continued till the counter reaches Tz. Thus PWM signals for one switching period are generated. Now the counter is set to zero and again same procedure is repeated for new values of $V_{\text {ref }}$ Thus symmetrical PWM signals are continuously generated.

The table shows the comparison of resource utilization for conventional SVPWM and simplified SVPWM algorithm implemented using Xilinx Spartan 3 FPGA (XC3S500E) operating at $50 \mathrm{MHz}$.

TABLE V

COMPARISION OF SVPWM SCHEMES IMPLEMENTED USING SPARTEN 3 FPGA OPERATING AT 50MHZ

\begin{tabular}{|l|c|c|c|c|c|}
\hline Scheme & Multipliers & Dividers & $\begin{array}{l}\text { Adders } \\
\text { /Subtra } \\
\text { ctors }\end{array}$ & CLB's & $\begin{array}{l}\text { \% } \\
\text { Utiliz } \\
\text { ation }\end{array}$ \\
\hline $\begin{array}{l}\text { Conve- } \\
\text {-ntional }\end{array}$ & 8 & 2 & $24+$ & 1796 & $15 \%$ \\
\hline Proposed & $\mathbf{0}$ & $\mathbf{0}$ & $\mathbf{3 2 +}$ & $\mathbf{4 9 0}$ & $\mathbf{4 \%}$ \\
\hline
\end{tabular}

\section{5) Dead time generation module}

In ideal conditions, the gating signals to the power switches of same phase leg of the PWM inverter should be complementary. However, the turn-off time of a power switch is usually longer than its turn-on time. So, if the switching is carried out simultaneously, the device turns on quickly as compared to other device which is supposed to be turned off. This can cause short circuit due to both switches of the same leg being on at the same time. This can damage the switches as well as coil of motor. So this condition must be avoided. It is done by delaying the switching on of a device than switching off of its complementary device. An appropriate delay time must be inserted between these two gating signals. The length of this delay time is usually about 1.5 to 2 times the maximum turn-off time. The following diagram shows how the dead-time is inserted between two PWM signals of the same leg. Dead time generation module is the part of the symmetric PWM generation algorithm.

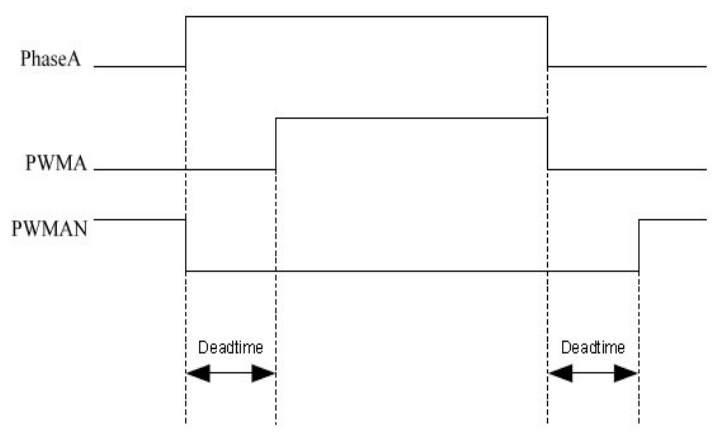

Figure 6 Dead time generation for PWMA

The scheme shown in figure (6) is implemented in the algorithm. As seen from the figure, the switching on of upper switches of VSI is delayed by dead time value which is configurable. The switching off of lower switches of VSI is delayed by dead time value. Thus short circuiting is prevented.

\section{EXPRIMENTAL VERIFICATION OF ALGORITHM}

The scheme implemented for testing of the algorithm is as shown in figure (1). Figure (7) shows experimental setup. The DAQ card from National Instruments is used for generation of three 120 degree phase shifted variable frequency sine waves as $\mathrm{V}_{\mathrm{a}}, \mathrm{V}_{\mathrm{b}}$ and $\mathrm{V}_{\mathrm{c}}$ interfaced with $\mathrm{Lab}$ VIEW software. These voltage waveforms are given to SPI based 12-bit ADC MCP3204. It is set to scan three channels continuously. The ADC continuously samples the three sine wave inputs by its minimum sampling time and digital values are continuously accepted by FPGA. Thus FPGA gets the values of $V_{a}, V_{b}$ and $V_{c}$ i.e. after calculation $V_{\text {ref }}$ for SVPWM generation.

The SVPWM generation algorithm is executed in FPGA. It produces six PWM signals output. The PWM signals from FPGA act as switching signals for IGBT's of VSI. In place of motor, star connected resistive-inductive load is used. The output of VSI is given to this resistive load. To filter the load voltage, low pass RC filters are used. To observe the outputs, Tektronix DSO with 4 input channels is used which has waveform storage function. After testing on R-L load, the algorithm is tested on three phase induction motor. The result matches those of the simulated R-L load.

\section{Motor Parameters}

Rated Voltage $230 \mathrm{~V}$

Three Phase rating $1.5 \mathrm{KW}$ 


$\begin{array}{lll}\text { No of poles (P) } & : & 4 \\ \text { Frequency (f) } & : & 50 \mathrm{~Hz} \\ \text { Power rating } & : & 3 \mathrm{hp} \\ \text { Stator Resistance (Rs) } & : & 4.6933 \mathrm{Ohm} \\ \text { Rotor Resistance (Rr) } & : & 4.4374 \mathrm{Ohm} \\ \text { Stator Leakage reactance (Xls) } & : & 4.85737 \mathrm{Ohm} \\ \text { Rotor Leakage reactance (Xlr) } & : & 7.12623 \mathrm{Ohm} \\ \text { Moment of inertia } & : & 0.01218\end{array}$

Figure 7 shows the SVPWM pulses of $6.25 \mathrm{KHz}$ frequency. Figure 8 and 9 shows the line-to line voltage and line-to-neutral voltage waveforms respectively.

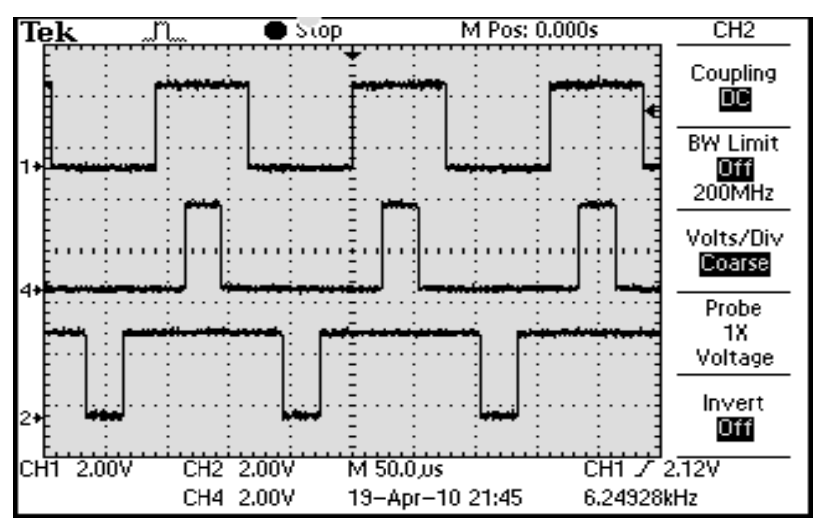

Figure 7 Experimental results of output SVPWM pulses

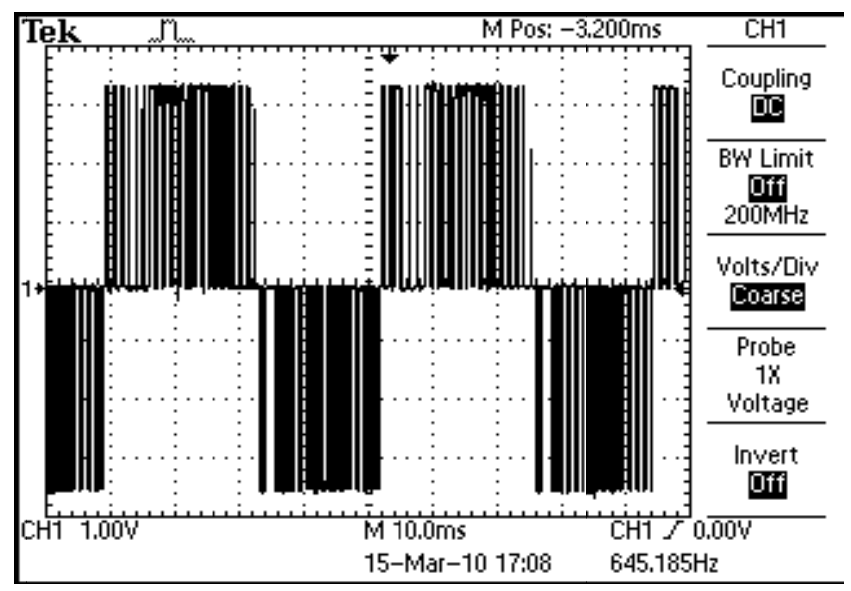

Figure 8 Experimental result of line-to-line voltage

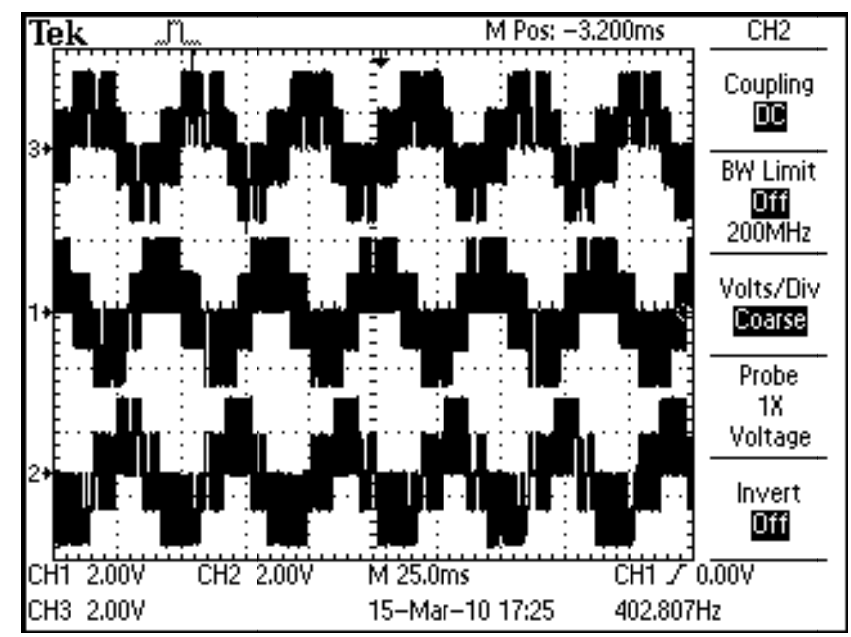

Figure 9 Experimental result of line-to-neutral voltage

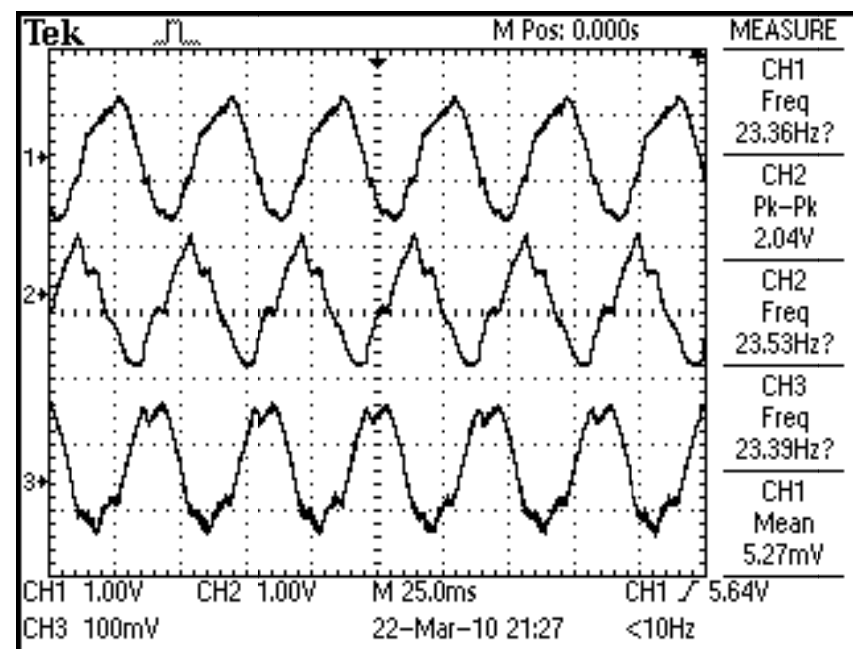

Figure 10 Experimental result of filtered load current

Figure 11 shows the comparison between expected fundamental frequency in $\mathrm{Hz}$ and output fundamental frequency in $\mathrm{Hz}$ at the step size of $5 \mathrm{~Hz}$, the graph shows the output frequency is matching with expected fundamental frequency.

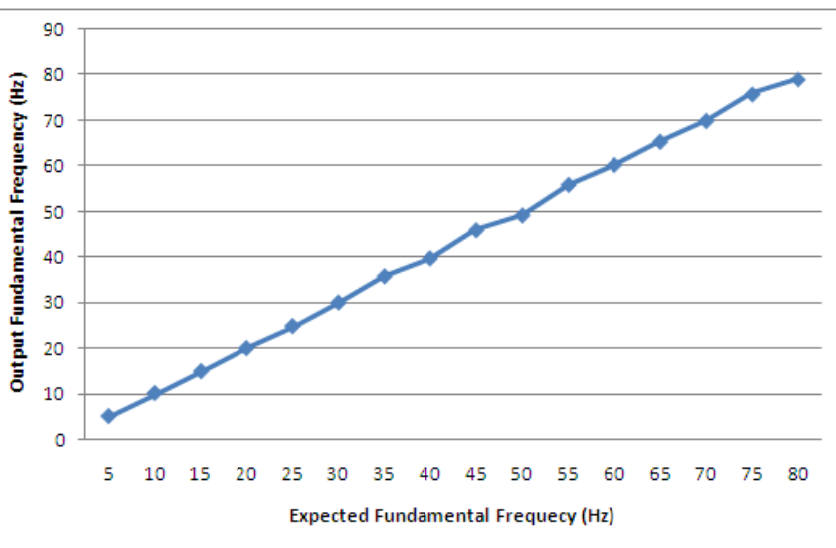

Figure 11 Experimental result of Output fundamental frequency versus expected fundamental frequency with step size of $5 \mathrm{~Hz}$ 


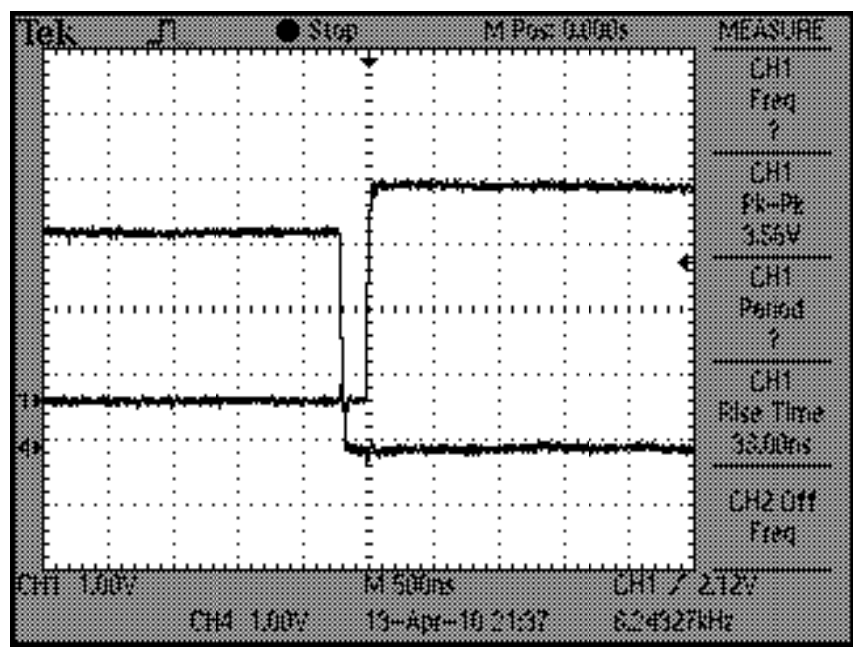

Figure 12 Experimental results of dead time generation module

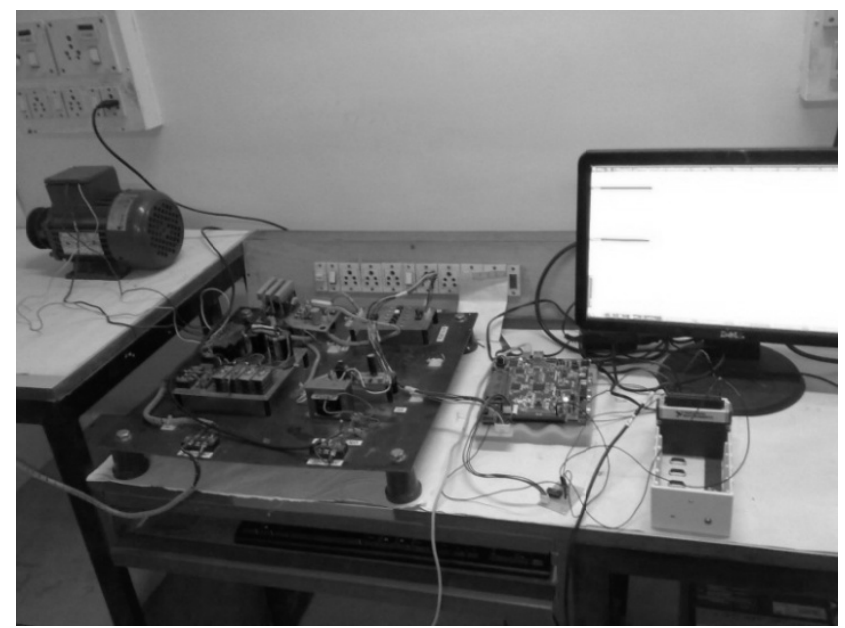

Figure 13 Experimental set-up

\section{CONCLUSION}

In context with digital implementation of Space Vector PWM algorithm for three phase inverter used for 3-phase induction motor, a simplified and resource efficient algorithm is proposed in this paper. Experimental results are provided to verify the feasibility and validity of proposed algorithm. The algorithm is implemented using Xilinx Spartan 3 FPGA and tested for the fundamental frequency ranging from $0.5 \mathrm{~Hz}$ to $1500 \mathrm{~Hz}$ and switching frequency ranging from $200 \mathrm{~Hz}$ to $50 \mathrm{KHz}$. The algorithm is so simple to digitally implement as it uses only adders, subtractors and decoders. The same can be implemented using conventional Microcontrollers or DSP processors and will get faster execution time. The VSI model used to test the algorithm is two-level VSI but the same can be used for multilevel VSI with some modifications in algorithm.

\section{REFERENCES}

[1] Ying-Yu Tzou, and Hau-Jean Hsu "FPGA Realization of SpaceVector PWM Control IC for Three-Phase PWM Inverters" IEEE Transaction on Power Electronics, Vol. 12, No.6, Nov. 1997

[2] Prawin Angel Miachael, Dr.N.Devrajan, "FPGA implementation of Multilevel Space Vector PWM Algorithms" International Journal of Engineering and Technology, Vol. 1, No.3, August 2009 ISSN:17938236
[3] Atif Iqbal, Adoum Lamine, et.al. "MATLAB/SIMULINK Model of Space Vector PWM for Three-Phase Voltage Source Inverters." Universities Power engineering Conference, 2006, New castle

[4] Z. Keliang and W. Danwei, "Relationship between space-vector modulation and three-phase carrier-based PWM: A comprehensive analysis," IEEE Trans. Ind. Electron., vol. 49, no. 1, pp. 186-196, Feb. 2002.

[5] Zeliang Shu, Jian Tang, et.al. "An Efficient SVPWM Algorithm with Low Computational Overhead for Three-Phase Inverters" IEEE Transaction on Power Electronics, Vol.22, No.5, Sep. 2007

[6] Simin Jiang, Jiangang Liang, et.al. "Modeling and Co simulation of FPGA- Based SVPWM Control for PMSM" Industrial Electronics Society 2005 IECON 2005, $31^{\text {st }}$ Annual Conference of IEEE

[7] C.L.Toh, N.R.N.Idris, et.al. "Design and Implementation of TMS320C31 DSP and FPGA for Conventional Direct Torque Control (DTC) of Induction Machines." Proceedings of world academy of science, engineering and technology, volume 38, Feb 2009

[8] A. M. Trzynadlowski, et.al. "An integral Space-Vector PWM Technique for DSP-Controlled Voltage Source Inverters" IEEE transaction on industry applications, Vol. 35, issue 5, 1999, 1091 1097

[9] Amit Kumar Gupta, et.al. "A Space Vector PWM Scheme for Multilevel Inverters Based on Two- level Space Vector PWM" IEEE Transaction on Industrial electronics, Vol. 53, issue: 5, 2006

[10] Ma Fengmin. Yang Tao. et.al. "A Novel Simplified SVPWM Control Scheme for AC/DC Voltage-Source Converters" Asia-Pacific Conference on Environmental Electromagnetic. CEEMI 2000 May 37, 2000, Shanzhai, China

[11] Su Chen, Gkza Jobs "Symmetrical SVPWM Pattern Generator Using Field Programmable Gate Array Implementation" $7^{\text {th }}$ Annual IEEE Applied Power Electronics Conference and Exposition, 2002, APEC 2002, Dalas

[12] Nikola Celanovic, et.al. "A Fast Space-Vector Modulation Algorithm for Multilevel Three-Phase Converters" IEEE Transactions on Industrial Applications, Vol. 37, No.2 march/April 2001

[13] Zhaoyong Zhou and Tiecai Li, et.al. "Design of a Universal Space Vector PWM Controller Based on FPGA" $19^{\text {th }}$ annual IEEE Applied Power Electronics Conference and Exposition, 2004, APEC 04

[14] Wei-Feng Zhang and Yue-Hui Yu "Comparison of Three SVPWM Strategies" Journal of Electronics Science and Technology of China, Vol. 5, No.3, Sep 2007

[15] E.Monmasson, Y. A. Chapuis, "Contributions of FPGA's to the Control of Electrical Systems, a Review", IEEE industrial Electronics Society Newsletter 49/(4)

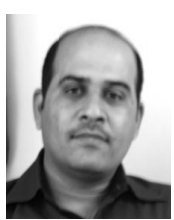

D. N. Sonawane Assistant Professor, Department of Instrumentation and Control, College of Engineering, Pune, India. He received B. E. in Instrumentation and Control form S. G. G. S. College of Engineering, Nanded in 1997 and ME from College of Engineering, Pune in 2000. He is currently pursuing doctoral research at Pune University. His research area includes FPGA (IP Core development) and Embedded System. $\mathrm{He}$ is a member of Instrument Society of India (ISOI) and Biomedical Society of India (BMESI)

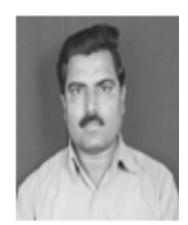

Dr. Mukul Sutaone, Professor and Head, Department of Electronics and Telecommunication, College of Engineering, Pune, India. He received B. E. in Electronics form V. R. C. College of Engineering, Nagpur and M E in Electronics and Telecommunication form College of Engineering, Pune. He received his $\mathrm{PhD}$ in Texture analysis form University of Pune; his research area includes signal processing and communication. 
Dr. Bhalchandra Choudhari, Professor and Head, Department of Electrical Engineering, College of Engineering, Pune, India. He received B. E. and M.E in Electrical Engineering from Govt. College of Engineering, Aurangabad. He received his $\mathrm{PhD}$ form Indian Institute of Technology, Bombay (IITB) in Machine Design; his research area includes AC-DC machine modeling, design and analysis. 